\title{
What's the value of a star? Actor familiarity and likeability effects on emotional mimicry of cinematic displays
}

$\$$ sciendo

ELEN LOTMAN, Tallinn University, Estonia, elen.lotman@tlu.ee ALAN VOODLA, Tartu University, Estonia, alanvoodla@gmail.com ANDERO UUSBERG, Tartu University, Estonia, andero.uusberg@ut.ee 


\section{ABSTRACT}

Researchers and practitioners have long been intrigued by the role of stars in the film industry (McDonald 2005). Actors with star status can enhance the economic prospects of a film (Wallace et al. 1993). For instance, replacing average stars with top stars has been shown to increase revenue (Nelson, Glotfelty 2012). A meta-analysis of 61 studies collating data from 1545 films has shown the significant effect of commercial star power on Hollywood films' revenues (Hofmann, et al. 2017). The Hollywood movie industry can be viewed as a system that maintains and regulates the popularity of existing and emerging stars through agents, producers and award systems (McDonald 2013).

\begin{abstract}
Yet it is unclear why the phenomenon of stardom arises. According to one hypothesis, the fact that stardom is more evident in Hollywood revenue-dependent filmmaking than in independent filmmaking, suggests that stars activate some psychological inclinations that motivate people to see a movie (Cutting et al. 2011; Cutting et al. 2010; Del Vecchio et al. 2018; Silver 2007). Given that stars as "inputs" to filmmaking are expensive both in terms of salary and special demands, it would not make sense to pay more for an otherwise equivalent "input" (there are probably thousands of talented actors among the unknown faces) unless audiences responded more favourably to a star than to a lesser known actor. This suggests that by developing and maintaining the star system, Hollywood taps into some psychological mechanism that makes general audiences' respond more favourably to stars. It is therefore highly likely that the star system is one way in which Hollywood film producers cope with the unparalleled dependence on audience revenue (Hollywood has not had any official state support system, as opposed to most of the rest of the world). Different accounts
\end{abstract}

on the European star system consider it a rare phenomenon (Hedling 2009), suggesting that European stardom should be appreciated differently (Soila 2009), that one of the differences comes from the lack of the industrial construction of the star's image (Vincendeau 2000). Yet, the potential of the stardom phenomenon to also occur in Europe is clearly visible, and one of the issues connected with it has been that the faces on the screen are charming but unrecognizable (Hedling 2014).

This poses a question - what kind of psychological mechanism could make people prefer to see familiar faces acting as different characters? In a way, star preference is quite paradoxical, as seeing the same faces in different roles might work against the phenomenon of suspension of disbelief (Ferri 2007), because recognizing an actor playing a character should theoretically remind the audience that the character is not real. Why do audiences nevertheless prefer to see the same faces in different roles? Part of the answer could involve empathetic reactions to stars. It is known that more familiar individuals elicit stronger contagion of emotion, not only in 
the general human population (Norscia, Palagi 2011), but also in children with autism (Hudry, Slaughter 2009), chimpanzees (Campbell, de Waal 2011) and dogs (Romero et al. 2013). Emotional contagion, a phenomenon of someone's emotions and related behaviour causing the elicitation of similar processes in others, has generally been described as a primitive part of an empathetic response (Shamay-Tsoory 2011). We therefore hypothesized that stars are preferred by audiences in part because familiar and likeable actors induce stronger empathic reactions.

In this study, we tested this hypothesis by measuring facial emotional mimicry the automatic and unconscious mirroring of others' facial expressions of emotion of emotional expressions in cinematic displays by three well-known Estonian actors. To assess the star status of the actors, we measured how familiar and likeable each actor was to each study participant. If our hypothesis stands and stardom has implicit effects on empathic reactions, we should observe stronger empathic responses for higher levels of familiarity and/or likeability. Specifically, we expect that familiarity and/ or likeability increase self-rated affect as well as facial emotional mimicry elicited by actors displaying emotional expressions in short clips.

\section{METHODS}

We used data from an experiment that was originally designed to assess the effect of cinematic lighting on empathic reactions. Here, we provide a summary of the methods; for full details see Voodla et al (2020, forthcomin).

In the experiment, three well-known female actors displayed three emotions (happiness, anger, and disgust) in two lighting conditions (the latter not distinguished in the present analyses). We recorded the perceived familiarity and perceived likeability of each actor by asking each participant to rate "How familiar this actress is to you?" and "How likable this actress is to you?", respectively. The dependent variables included participants' assessments of
(1) the affective feelings recognized in actors, (2) experienced by themselves, and, (3) electromyographic (EMG) activity recorded from three facial muscles in five-time windows.

\section{SAMPLE AND PROCEDURE}

The final sample of 41 participants (mean age $=26.59, \mathrm{SD}=5.95 ; 11$ males) consisted of volunteers recruited from the University of Tartu.

Upon arrival to the lab, each participant signed an informed consent form and was seated 1 metre from a stimulus monitor. They were told that the purpose of the experiment was to study cinematic emotional experiences. The EMG electrodes were then placed according to the instruction of electromyographic research with human subjects (Fridlund, Cacioppo 1986). Participants were then instructed to view video clips and evaluate the valence and intensity of their own emotional experiences and those of the displayed actors. During the experiment, each participant was alone in a dimly lit room. Each experimental session lasted approximately 30 minutes. After the experiment, participants completed a questionnaire that included the familiarity and likeability ratings.

\section{STIMULI AND DESIGN}

The participants viewed 5 -second video clips on a 19-inch monitor. In each clip, actor's facial expressions changed from an initially neutral state to a state expressing either anger, happiness, or disgust. The actresses were well-known to most participants. The 18 unique clips (3 actors expressing 3 different emotions under 2 lighting conditions) were presented twice in randomized order within a block of 36 trials. One presentation of a clip was followed by affective ratings of the participants' emotion and the other by affective ratings of the actor's emotion. The experiment comprised of 3 blocks with a total of 108 trials.

\section{MEASURES}

After each clip, participants were asked either about the emotion of the actor 
("Using the scales below, please characterize the emotion experienced by the person in the clip") or about their own emotions ("Using the scales below, please characterize the emotion you experienced during the clip"). Participants responded using two consecutive visual-analogue scales measuring valence ("Was the emotion pleasant or unpleasant?"; 0 "Unpleasant" and 100 "Pleasant") and intensity ("Was the emotion strong or weak?"; 0 "Weak" and 100 "Strong"). Given that valence and intensity are related, we converted participant responses to these questions into a single affective response strength score for each emotion under investigation: happiness strength = valence + intensity; anger and disgust strength $=(100-$ valence $)+$ intensity.

Facial mimicry reactions were measured with electromyography. Previous research has shown that facial expressions of discrete emotions activate relatively discrete facial muscle groups which include Zygomaticus Major for happiness, Corrugator Supercilii for anger, and Levator Labii for disgust (Dimberg et al. 2000; Lundqvist 1995). To measure activity within these muscles, we placed 8 electrodes on participants facial skin (2 for each muscle to enable bipolar reference) following the instruction of electromyographic research with human subjects (Fridlund, Cacioppo 1986). Electrical potentials from the facial muscles were recorded using BioSemi ActiveTwo system with sampling rate of $512 \mathrm{~Hz}$. The pre-processing of EMG signal was conducted with Matlab and EEGLAB (Delorme, Makeig 2004) software following standards in the literature (for details see Voodal et al., in press).

For every stimulus, the average EMG activity, 1000 ms before stimulus onset, was subtracted from the activity during the stimulus presentation. The pre-processed signal was averaged within 5-time windows: 1000-2000 ms, 2000-3000 ms, 3000-4000 ms, 4000-5000 ms. Trials were removed as artefacts if they included amplitude deviations larger than 5 SD from the baseline or if their value distributions differed more than 5 SD from participant average (EEGLAB autorej function).

Manipulation check analyses reported in Voodla, et al. (2020, forthcoming) revealed that the facial muscle showing the strongest activity to displays of disgust was zygomaticus rather than the levator, which suggested that we did not observe facial mimicry of disgust. We therefore excluded disgust clips from further analysis since we cannot test familiarity and likeability effects on facial mimicry without a valid mimicry signal.

\section{STATISTICAL ANALYSIS}

The data were analysed in the statistical computing environment RStudio (RStudio Team 2015). For many analyses, we fit linear mixed-model regressions with empathic response measures as the dependent variable. In these models, we included a random participant factor to statistically control for individual differences in responsiveness to all actors and a random actor factor to control for mean actor effects on all participants. These models were optimized to detect covariance between familiarity and likeability ratings and dependent variables.

\section{RESULTS \\ MANIPULATION CHECKS}

We conducted a series of preliminary analyses to confirm that the stimuli elicited expected affective and mimicry responses. First, we analysed the self-reported strength of affective states experienced either by the actors or by the participants themselves (see Figure 1). According to a mixed model analysis of the data, participants rated actors' emotion to be stronger than their own (std. beta $=-0.64$, SE $=0.04$, $p<.001)$ and happiness to be stronger than anger (std. beta $=0.84$, SE $=0.04, p<.001$ ), in particular, in their own experience (std. beta $=-0.26$, SE $=0.05, p<.001$ ).

Next, we analysed facial mimicry, or the electromyographic activation relative to prestimulus baseline in facial muscles corresponding to the displayed emotion: Zygomaticus major for happiness and 


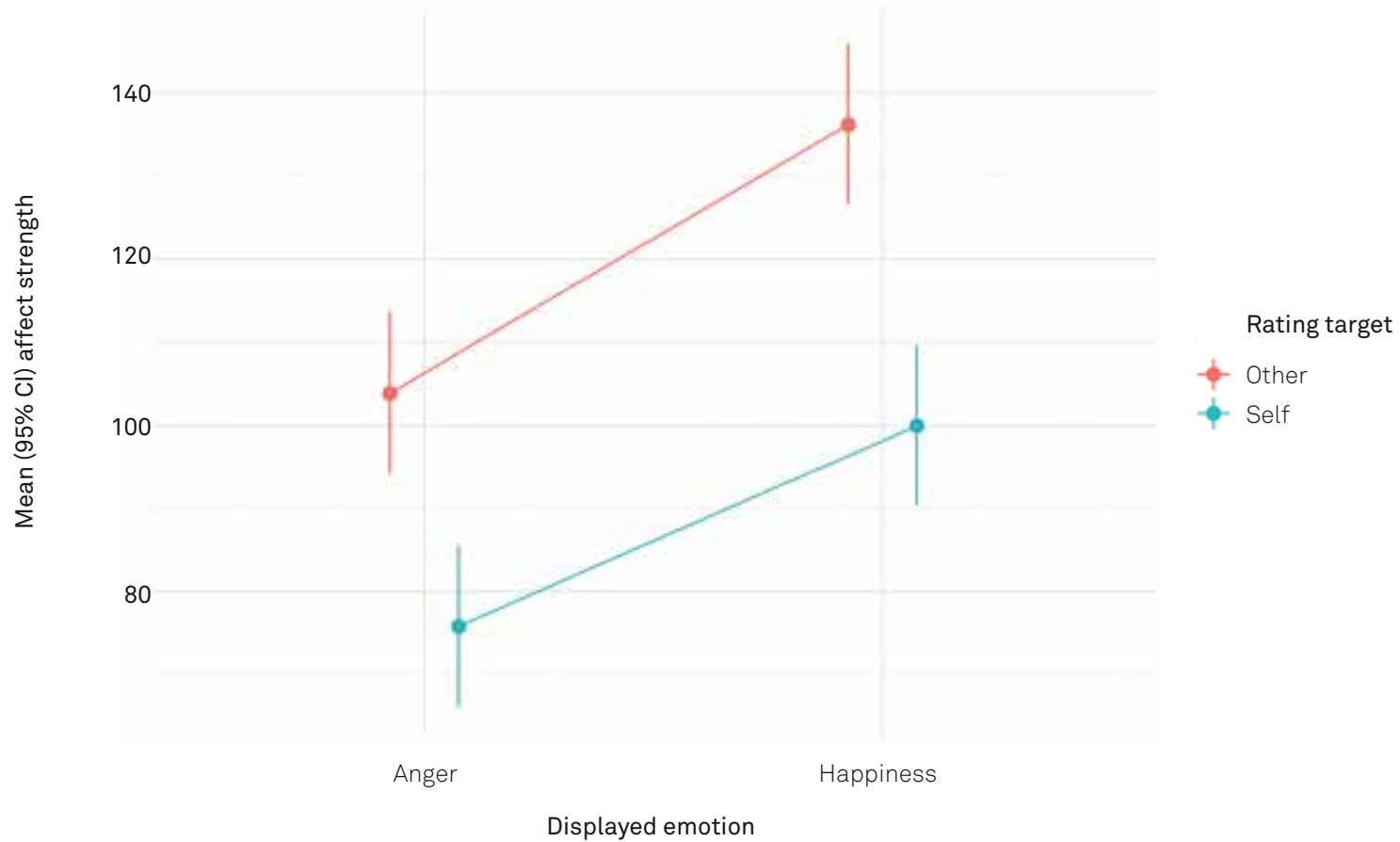

FIGURE 1. Rated strength of the affective states displayed by actors and experienced by participants. Bars denote the $95 \%$ confidence intervals.

0.2

0.3

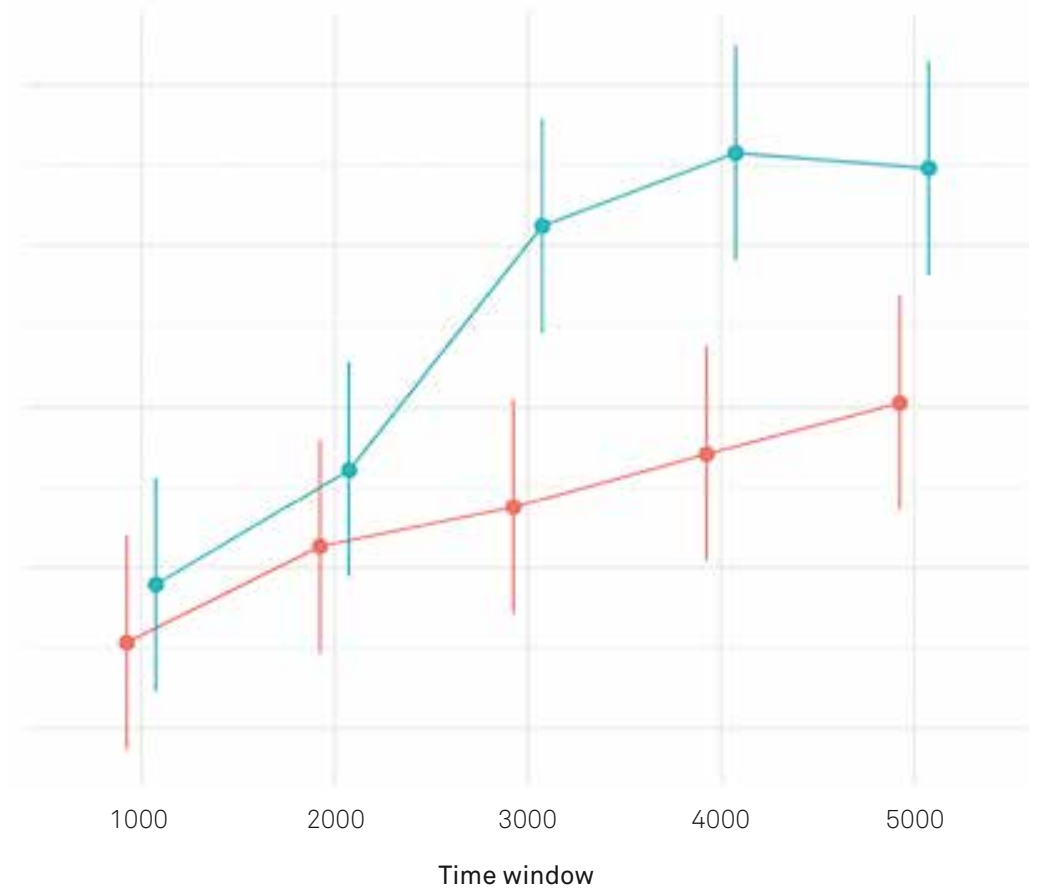

Displayed emotion

0.1

0.0

$-0.1$

FIGURE 2. Facial mimicry of happiness in Zygomaticus Major and anger in Corrugator supercilii. Bars denote the $95 \%$ confidence intervals. 
A. Familiarity effect on affect strength

Other Self

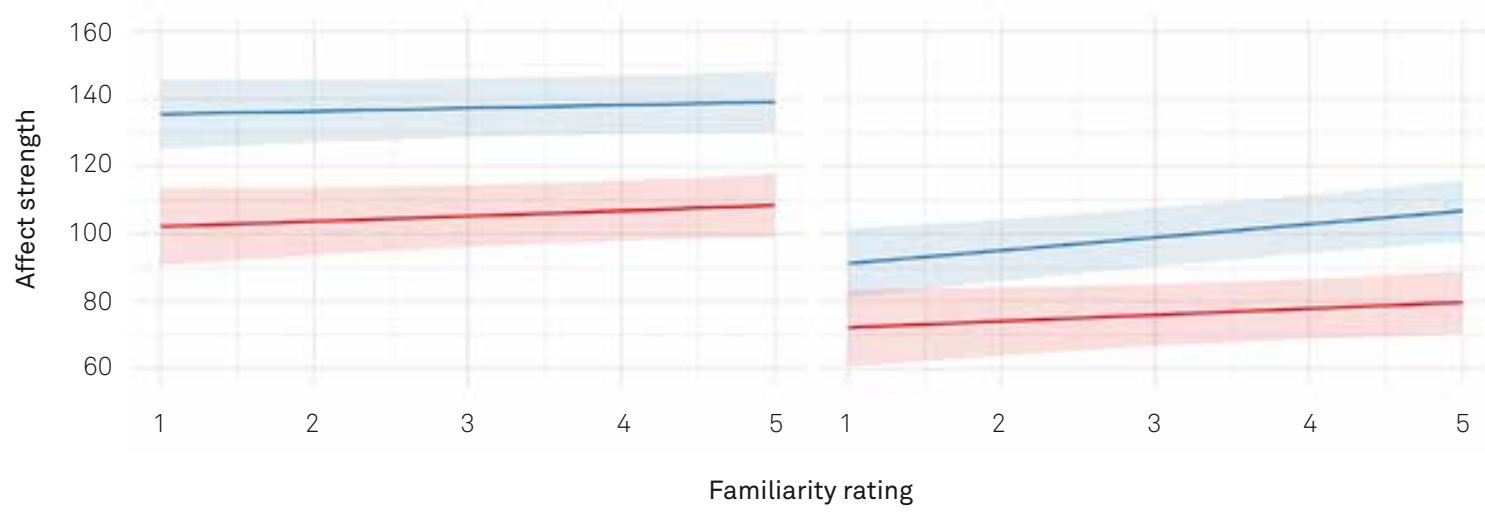

Displayed emotion $\quad \square$ Anger $\quad \forall$ Happiness

A. Likeability effect on affect strength

Other Self

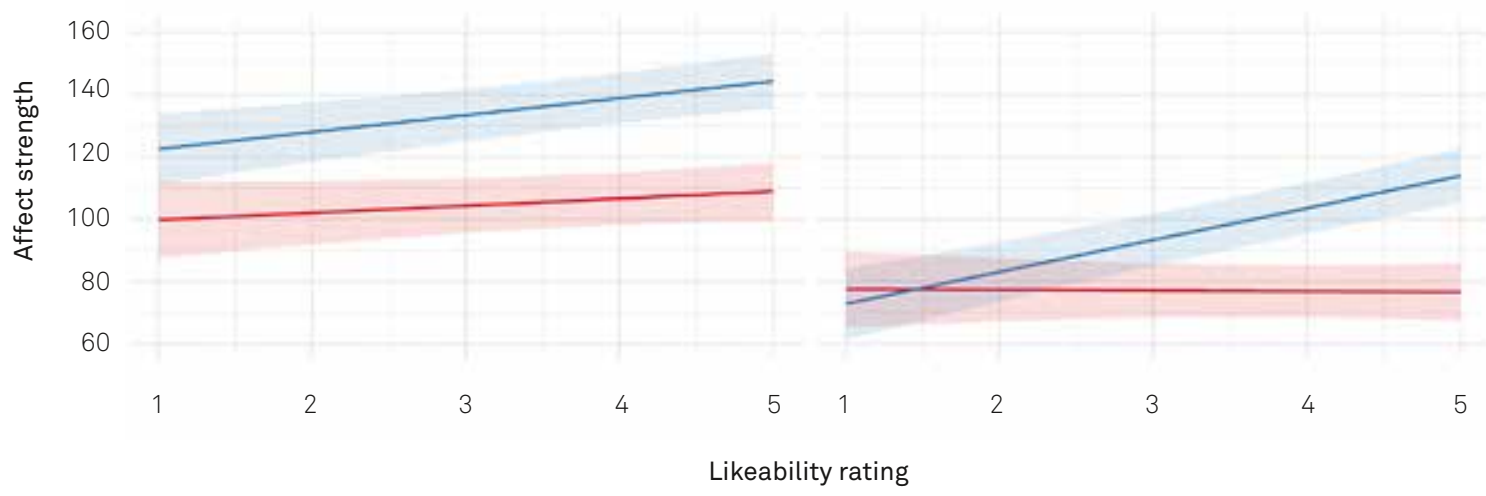

FIGURE 3. Familiarity and likeability effects on self-reported affective strength predicted by the mixed regression models in Table 1 . Ribbons denote the $95 \%$ confidence intervals. 
Predictors

Rating
Target [Self]
emotion [Happiness]
Rating* Target [Self]
Rating* emotion [Happiness]
emotion [Happiness]* Target [Self]
Rating * emotion [Happiness]* Target [Self]
Random Effects
$\sigma^{2}$
$T_{00}$
ICC
$\mathrm{N}$

Observations

Marginal $R^{2}$ / Conditional $R^{2}$

* $p<0.05 * * p<0.01 * * * p<0.001$
Familiarity

model

Likeability model

std. Beta

std. Beta

0.07

$-0.82 * * *$

$-0.82 *$

$0.87 * * *$

0.88 *

0.01

$-0.07$

$-0.03$

0.09

-0.18 *

$-0.19 * \star$

0.12

$0.21 * *$

341.56

319.39

460.94 subject

450.35 Subject

7.99 actor

3.02 actor

0.58

0.59

32 subject

32 subject

3 actor

3 actor

640

640

$0.373 / 0.736$

$0.402 / 0.753$

TABLE 1. Familiarity and Likeability effects on self-reported affective strength. 
Corrugator supercilii for anger. As Figure 2 illustrates, facial muscle activity increased throughout the 5 seconds of the clip duration, mirroring gradual unfolding of the expressions on the actors' faces. According to a mixed model analyses of these data, for both emotions, the mimicry effect was significant from the 1000-2000 ms time window onward (std. beta increasing from 0.06 to $0.14, p<0.01$ ) and was significantly larger for happiness than for anger from 2000-3000 ms time window onwards (std. beta ranging between 0.11 and 0.15 , $\mathrm{p}<0.001)$.

As independent variables, we used the familiarity and likeability ratings of actors provided by participants at the end of the experiment. On average, the actors were rated $3.73(S D=1.53)$ on the familiarity scale and $3.79(S D=1.04)$ on the likeability scale. The ratings were correlated at $r$ $=0.41(p<0.001)$ which means that about $17 \%$ of variance in likeability can be accurately predicted from familiarity and vice versa. This suggests that familiarity and likeability of an actor are related, but not interchangeable aspects of the perceived stardom of actors, justifying our decision to analyse these aspects separately.

\section{HYPOTHESIS TESTS}

As a first test of our hypothesis, we used a pair of mixed model regressions to analyse how familiarity and likeability ratings related to affective strength. The results can be found in Table 1 and are illustrated in Figure 3. The findings include the effects of rating target (actor affect is rated stronger than own affect) and emotion (happiness is rated stronger than anger) that were expected based on the manipulation check analyses above. Focusing on the novel main and interactive effects of familiarity and likeability ratings, the analyses revealed that familiarity did not have any statistically significant effects on self-reported affective strength. However, a significant three-way interaction suggests that the perceived likeability of actors increased the strength of happiness, but not anger, felt by the participants.
Next, we turned to analysing the familiarity and likeability effects on facial mimicry using a similar pair of mixed model regressions. The results are illustrated in Figure 4 and Table 2. The electromyographic findings mirror the self-reported findings, in that familiarity ratings did not have a significant effect on facial mimicry. By contrast, the likeability ratings had a clear effect on facial mimicry of happiness from the third time window onward, which reached statistical significance by the fifth time window.

\section{DISCUSSION}

We hypothesized that one of the ways in which stars add value to a film is by eliciting stronger empathic reactions in viewers compared to unfamiliar and less likeable actors. We found partial support for this hypothesis: positive emotion contagion, expressed both as self-reported feelings and as recorded facial mimicry, was correlated with the likeability, but not with the familiarity of the actors to the individual viewer.

Beyond broadly supporting our hypothesis, these findings have several interesting implications. First, we found that stardom enhanced empathic reactions to happiness, a positive emotion, but not to anger, a negative emotion. This may suggest that the star status of an actor may matter more to the extent to which audiences empathize with positive emotional experiences. Interestingly, there is a tendency in Hollywood to cast stars in varied protagonist roles while the antagonists are often played by type-casted "bad guys". Our findings suggest that in this casting pattern a star can indeed make it slightly more likely that viewers share the positive emotions of protagonists rather than antagonists.

Second, we found that familiarity alone did not significantly impact emotional contagion whereas likeability did. It is important to remember that familiarity and likeability were correlated in our data, suggesting that they are distinct but related features of stardom - or in the case 
A. Familiarity effect on facial mimicry

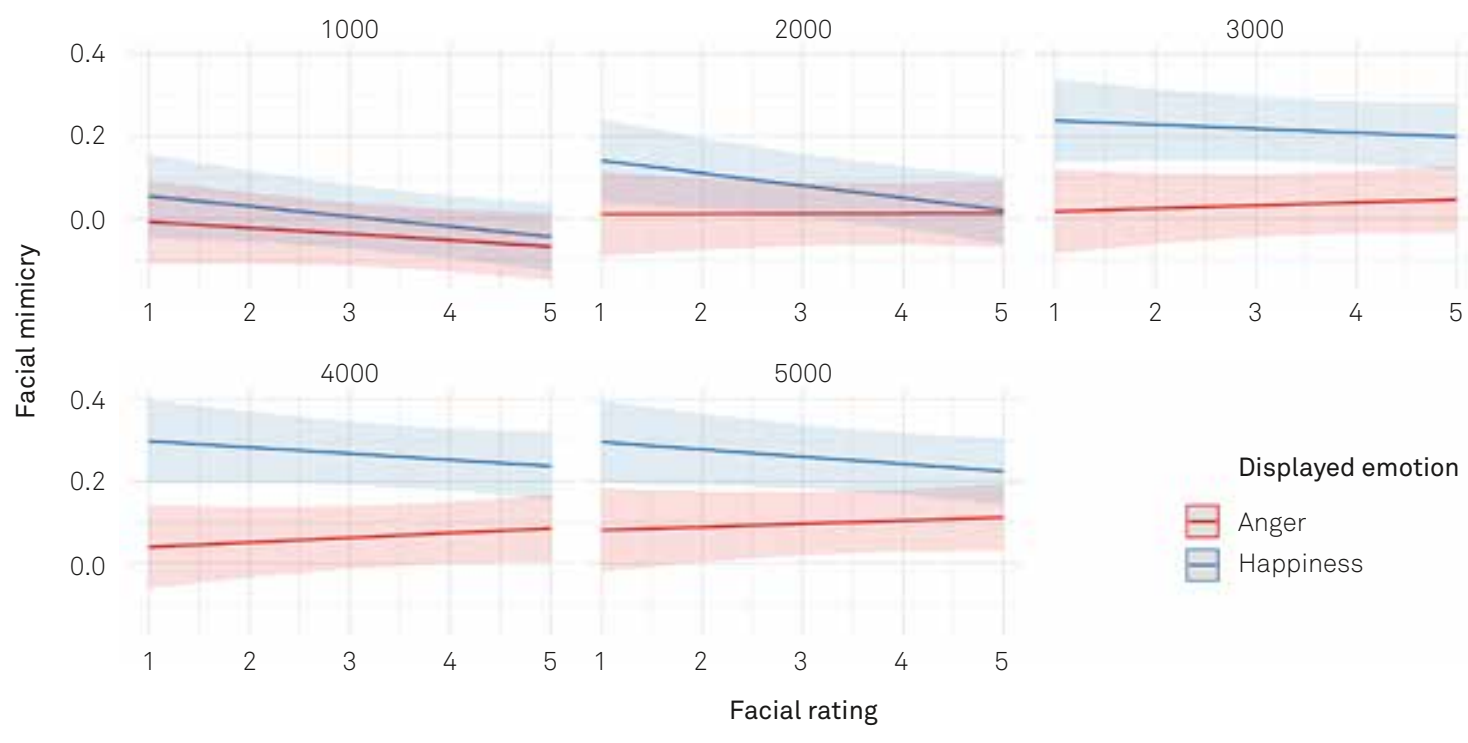

A. Likeability effect on facial mimicry

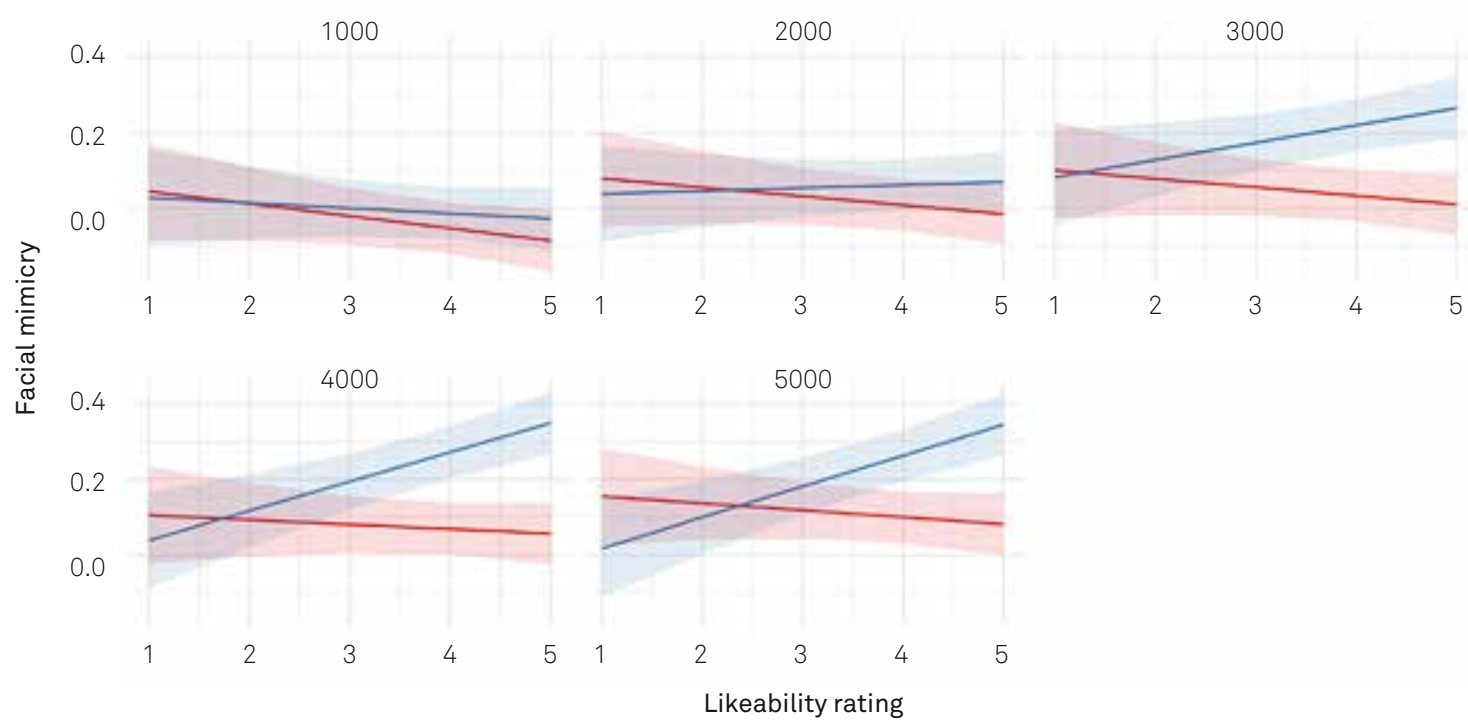

FIGURE 4. Familiarity and likeability effects on facial mimicry predicted by the mixed regression models in Table 2 . Ribbons denote the $95 \%$ confidence intervals. 


\begin{tabular}{|c|c|c|}
\hline \multirow[b]{2}{*}{ Predictors } & \multirow{2}{*}{$\begin{array}{l}\text { Familiarity } \\
\text { model } \\
\text { std. Beta }\end{array}$} & \multirow{2}{*}{$\begin{array}{l}\text { Likeability } \\
\text { model } \\
\text { std. Beta }\end{array}$} \\
\hline & & \\
\hline Rating & -0.07 & -0.10 \\
\hline emotion [Happiness] & 0.11 & 0.11 \\
\hline Time_window [2000] & 0.18 & 0.18 \\
\hline Time_window [3000] & 0.25 & 0.25 \\
\hline Time_window [4000] & 0.35 & 0.35 \\
\hline Time_window [5000] & 0.44 & 0.44 \\
\hline Rating * emotion [Happiness] & -0.05 & 0.06 \\
\hline Rating * Time_window [2000] & 0.07 & 0.03 \\
\hline Rating * Time_window [3000] & 0.10 & 0.03 \\
\hline Rating * Time_window [4000] & 0.12 & 0.06 \\
\hline Rating * Time_window [5000] & 0.11 & 0.04 \\
\hline Time_window [2000] * emotion [Happiness] & 0.03 & 0.03 \\
\hline Time_window [3000] * emotion [Happiness] & 0.41 & 0.41 \\
\hline Time_window [4000] * emotion [Happiness] & $0.44^{*}$ & 0.44 \\
\hline Time_window [5000] * emotion [Happiness] & 0.32 & 0.32 \\
\hline Rating * Time_window [2000] * emotion [Happiness] & -0.10 & 0.04 \\
\hline Rating * Time_window [3000] * emotion [Happiness] & -0.03 & 0.15 \\
\hline Rating * Time_window [4000] * emotion [Happiness] & -0.08 & 0.21 \\
\hline Rating * Time_window [5000] * emotion [Happiness] & -0.07 & $0.24 *$ \\
\hline \multicolumn{3}{|l|}{ Random Effects } \\
\hline$\sigma^{2}$ & 0.09 & 0.08 \\
\hline \multirow[t]{2}{*}{$\tau_{00}$} & $0.02_{\text {Subject }}$ & $0.02_{\text {Subject }}$ \\
\hline & 0.00 actor & 0.00 actor \\
\hline ICC & 0.19 & 0.18 \\
\hline \multirow[t]{2}{*}{ N } & 40 Subject & 40 Subject \\
\hline & 3 actor & 3 actor \\
\hline Observations & 2400 & 2400 \\
\hline Marginal R² / Conditional R² & $0.096 / 0.269$ & $0.108 / 0.270$ \\
\hline
\end{tabular}

TABLE 2. Familiarity and Likeability effects on facial mimicry. 
of European cinema, the fame of the actor. It is reasonable to assume that familiarity and likeability are both necessary features of stardom. Familiarity alone does not guarantee star power, the actor has to also be likable. Likewise, being likeable alone does not guarantee star power, the actor also needs to be familiar. The aspect of recognizing an actor as an integral part of the star effect is supported by the history of conscious maintenance of on-screen facial continuity throughout the career within Hollywood stardom by actors themselves and professionals who are responsible for their looks - make-up artists, hairdressers, publicity photographers and cinematographers - who brought their faces to the audiences.

The impact of the appearance of faces in a film is strongly connected to the way they are lit. Similar lighting schemes on different films for the same actors keep the way they look consistent and bring out the facial features that audiences have perceived as likeable, adding to familiarity. Portrait light has therefore been part of the Hollywood star system, with famous actors often being filmed in the same lighting schemes throughout their career. For instance, the portrait lighting style called "butterfly light" or "Dietrich" was arguably developed because Marlene Dietrich insisted that she would always be lit in that way (Grey 2014) and that she used it meticulously (Henderson 2017). There is evidence that Josef Van Sternberg invented this light (Malkiewicz 2012) and that Dietrich was famous for controlling her image and, although her look changed over the years, her lighting did not (Stamberg 2017). Indeed, the facial characteristics that comprise the look that the audiences came to know as Marlene Dietrich comes out with this specific lighting and one of the goals could have been to maintain a constant look, to look like Marlene Dietrich, the familiar and likeable face the audiences expect to see. Likewise, Marilyn Monroe is known to have been lit often with lighting style that is known as "loop lighting". This also might have contributed to the consistency of her look, thus responding to audiences' need to recognize her looks quickly and effectively.

Cinematographers have developed specific styles to light specific actors in order to bring out the facial characteristics that they were known for. Beyond Dietrich and Monroe, there is evidence of this happening in the cases of Mary Pickford, Lilian Gish, Carole Lombard and Joan Crawford (Zimmerman 2010). One can argue that the reason for similar lighting used on same faces was not to consciously maintain likeability and familiarity, but to accentuate specific traits of a specific face thus producing similar-looking portrait shots, but in the end, the result stays the same - faces look consistently recognizable. Also, the systematic maintenance of the consistent look of the onscreen faces could be part of keeping Hollywood stars continually effective for audiences.

Likeability and familiarity may also reinforce each other. Previous exposure to stimuli is known to increase likeability through the mere exposure effect (Zajonc 2001). Familiarity with faces can also increase the accuracy and speed of emotion recognition, as has been shown in two studies on emotion recognition and cultural differences (Elfenbein, Ambady 2003). This suggests that, in line with the false fame effect, previous exposure may create a sensation that the person is more real. With brand names for example, the previous exposure has been shown to influence the perceived reality of the brand (Holden, Vanhuele 1999).

Juri Lotman refers to Pushkin's famous line, roughly translated as: "I will burst into tears over make-believe", which brilliantly characterizes the double nature of the artistic behaviour: while we can't possibly cry, being aware of fictionality of the character, paradoxically, the same feeling that makes us cry should also force us to forget that it is a make-believe. Lotman's view was that what really happens is that these opposite behaviours exist simultaneously and enrich each other, becoming the basis of the semantic organization of 
the literary text (Lotman 1998). Thus, it is also possible to interpret the dichotomy between recognizing an actor and caring for the character as a crucial part of the enjoyment of film art and we propose facial mimicry as one of the psychophysiological underpinnings of this interplay.

\section{REFERENCES}

Campbell, Matthew W.; de Waal, Frans B. M. 2011. 'Ingroup-Outgroup Bias in Contagious Yawning by Chimpanzees Supports Link to Empathy'. - PloS ONE 6(4): e18283. https://doi.org/10.1371/journal. pone. 0018283

Cutting, James E.; DeLong, Jordan E.; Nothelfer, Christine E. 2010. 'Attention and the Evolution of Hollywood Film'. - Psychological Science, 21(3), 432439. https://doi.org/10.1177/0956797610361679 Cutting, James E.; Brunick, Kaitlin L.; DeLong, Jordan E.; Iricinschi, Catalina; Candan, Ayse 2011. 'Quicker, Faster, Darker: Changes in Hollywood Film over 75 Years'. - I-Perception, 569-576. https://doi.org/10.1068/i0441aap Del Vecchio, Marco; Kharlamov, Alexander; Parry, Glenn; Pogrebna, Ganna 2018. 'The Data Science of Hollywood: Using Emotional Arcs of Movies to Drive Business Model Innovation in Entertainment Industries'. - Available at SSRN: https://ssrn.com/ abstract $=3198315$

Dimberg, Ulf; Thunberg, Monika; Elmehed, Kurt 2000. 'Unconscious facial reactions to emotional facial expressions'. - Psychological science, 11(1), 86-89. Elfenbein, Hillary Anger; Ambady, Nalini 2003. 'When familiarity breeds accuracy: Cultural exposure and facial emotion recognition'. - Journal of Personality and Social Psychology, 85(2), 276-290.

Ferri, Anthony J. 2007. Willing suspension of disbelief: Poetic faith in film. https://books.google.ee/books? $\mathrm{hl}=$ en $\& \mathrm{l} \mathrm{r}=\& \mathrm{id}=\mathrm{yB} \_Z O z \times q M V c C \& O \mathrm{i}=$ fnd $\& p g=P R 7 \& d q$ =suspension+of+disbelief\&ots=B7DhNE5Pln \&sig=-Z2COh2PxVDsLHcZg-APhd1jLel\&redir_ esc $=y \# v=$ onepage $\& q=$ suspension $\% 20$ of $\% 20$ disbelief\&f=false (15 November 2019)

Fridlund, Alan J.; Cacioppo, John T. 1986.

'Guidelines for human electromyographic research'. Psychophysiology, 23(5), 567-589.

Grey, Christopher 2014. Master Lighting Guide for Portrait Photographers. Retrieved from https://books. google.no/books?id=B7-9BQAAQBAJ\&printsec=frontc over $\# \mathrm{v}=$ onepage \&q\&f=false (18 November 2019) Hedling, Olof; Stoila, Tytti (eds.) 2009 Stellar encounters: stardom in popular European cinema. New Barnet: John Libbey Pub.

Hedling, Olof 2009 The Trouble with Stars: Vernacular vs. Global Stardom in Two Forms of European Popular Culture A Timoshkina, M Harrod \& M Liz (eds.), The Europeanness of European cinema: identity, meaning, globalisation.

Henderson, Amy 2017. 'The Pioneering Androgyny of Classic Hollywood Star Marlene Dietrich'. - Smithsonian.com, 29 June. https://www.smithsonianmag. $\mathrm{com} / \mathrm{smithsonian-institution/pioneering-androgyny-}$ classic-hollywood-star-marlene-dietrich-180963842/ (18 September 2019)

Hofmann, Julian; Clement, Michel; Völckner, Franziska; Hennig-Thurau, Thorsten 2017. 'Empirical generalizations on the impact of stars on the economic success of movies'. - International Journal of Research in Marketing, Volume 34, Issue 2.

Holden, Stephen J.; Vanhuele, Marc 1999. 'Know the name, forget the exposure: Brand familiarity versus memory of exposure context'. - Psychology \& Marketing, 16: 479-496. doi:10.1002/(SICI)15206793(199909)16:6<479::AID-MAR3>3.0.CO;2-Y

Hudry, Kristelle; Slaughter, Virginia 2009. 'Agent familiarity and emotional context influence the everyday empathic responding of young children with autism. Research in Autism Spectrum Disorders, 3, 74-85. Lotman, Elen 2017. 'Exploring the ways cinematography affects viewers' perceived empathy towards onscreen characters'. - Baltic Screen Media Review, 4, 88-105. 
Voodla, Alan; Lotman, Elen; Naar, Richard; Kolnes,

Martin; Uusberg, Andero forthcoming, 2020.

'Cinematographic high-contrast lighting can facilitate empathic affective mimicry'. - Projections: The Journal for Movies and Mind.

Lotman Juri M. 1998. Ob iskusstve. Sankt Peterburg: Iskusstvo-SPb.

Malkiewicz, Kris 2012. Film Lighting: Talks with Hollywood's Cinematographers and Gaffers. Retrieved from https://books.google.no/books?id=s-RfmJvqYyUC\&pg $=$ PA179\&dq=lighting+hollywood +faces \&hl=en\&sa=X \&ved=0ahUKEwigi7HOnMzjAhVms4sKHWQDDC0Q6AE

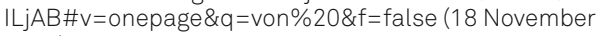
2019)

McDonald, Paul 2005. The Star System: Hollywood's Production of Popular Identities. Retrieved from shorturl.at/bviT5

McDonald, Paul 2013. Hollywood Stardom. Retrieved from shorturl.at/eDLM6

Nelson, Randy A.N Glotfelty, Robert 2012. 'Movie stars and box office revenues: an empirical analysis'. Journal of Cultural Economics, 36, 141-166.

Norscia, Ivan; Palagi, Elisabetta 2011. 'Yawn Contagion and Empathy in Homo sapiens'. - PloS ONE 6(12): e28472.

Shamay-Tsoory, Simone G. 2011. 'The neural bases for empathy'. - The Neuroscientist, 17(1), 18-24.

Silver, Jonathan Derek 2007. Hollywood's dominance of the movie industry: How did it arise and how has it been maintained? PhD diss, Queensland University of Technology. http://eprints.qut.edu.au/16687/ Stoila, Tytti 2009. Stellar encounters: stardom in popular European cinema. New Barnet: John Libbey Pub.

Stamberg, Susan 2017. 'Gallery Gives Movie Star Marlene Dietrich The Big-Picture Treatment' - NPR Illinois, 19 June. https://www.nprillinois.org/post/ gallery-gives-movie-star-marlene-dietrich-bigpicture-treatment\#stream/0 (18 September 2019) Vincendeau, Ginette 2009. World Cinema: Critical Approaches. Retrieved from: https://books.google.fi/ books? $h \mathrm{~h}=$ en $\& \mathrm{l} r=\& \mathrm{id}=$ SUKcAQAAQBAJ $\&$ o $=\mathrm{f} n \mathrm{f} \& \mathrm{pg}=\mathrm{PT}$ $46 \& d q=$ european+cinema + stardom\&ots $=H B 4 u 3 h Y L w$ w\&sig=v1 HfwQI0_Or5frwkWVDeULoYOhI\&redir_esc=y $\# \mathrm{v}=$ onepage \&q=stardom\&f=false (18 November 2019) Wallace, W. Timothy; Seigerman, Alan; Holbrook, Morris B. J Cult Econ 1993. 17: 1. https://doi.org/ 10.1007/BF00820765

Romero, Teresa; Konno, Akitsugu; Hasegawa, Toshikaza 2013. 'Familiarity Bias and Physiological Responses in Contagious Yawning by Dogs Support Link to Empathy'. - PloS ONE 8(8): e71365. https://doi.org/ 10.1371/journal.pone.0071365

Zajonc, Robert B. 2001. 'Mere Exposure: A Gateway to the Subliminal'. - Current Directions in Psychological Science, 10, 224. https://doi.org/Article

Zimmerman, Steve 2010. Food in the Movies. Retrieved from https://books.google.no/books?id=cZkcG-ftcaAC \&pg =PA13\&lpg=PA13\&dq=joan+crawford+image + lig hting\&source $=b \mid \& o t s=d v 9 \mathrm{cvaVDnf} \&$ sig $=\mathrm{ACfU} 3 \mathrm{U} 1 \mathrm{KS} 81$ ObDG0Tc8MM5TKdsC52bSPVw\&hl=en\&sa $=X \& v e d=2 a$ hUKEwjZmp7cpczjAhVj5aYKHXajChQ4ChDoATAHegQIB $x A B \# v=$ onepage $\& q=$ joan $\% 20$ crawford $\% 20$ image $\% 20$ lighting\&f=false (18 November 2019) 